\title{
RECURSOS LITERARIOS DE LA ÉPICA CLÁSICA PARA LA REPRESENTACIÓN DE LA GUERRA DE ARAUCO EN EL SIGLO XVI
}

\author{
María Gabriela Huidobro Salazar \\ Universidad Andrés Bello \\ mhuidobro@unab.cl
}

$\mathrm{U}$ na de las fuentes más relevantes para comprender la historia de la Guerra de Arauco, en el contexto de la conquista española de Chile en el siglo XVI, es el conjunto de poemas épicos escritos por autores hispanos a partir de sus experiencias, directas o indirectas, sobre el mismo conflicto: La Araucana de Alonso de Ercilla (1569-1590), Cuarta y quinta parte de La Araucana de Diego Santisteban (1598), Arauco domado de Pedro de Oña (1596), Purén indómito de Diego Arias (1603) y el poema anónimo La guerra de Chile (1610).

Sus testimonios no solo ofrecen valiosos registros sobre el proceso histórico que relataban, sino que constituyen también una fuente importante para conocer la cosmovisión y el bagaje cultural de sus autores, hombres de armas y de letras del Siglo de Oro español. Parte de dicho bagaje se constata en las influencias literarias y culturales que estos poemas traslucen. Sus versos ofrecen un testimonio de las lecturas a partir de las cuales los autores se habían formado, y que pudieron inspirar su propia percepción sobre la Guerra de Arauco.

En particular, destaca la influencia de las epopeyas griegas y romanas, que en algunos casos ha sido abordada en base a la noción de ecos, sugiriendo la idea de un fenómeno que repite elementos, pero que les otorga al mismo tiempo cierta variación respecto del original (Highet 1947; McManamon 1955: 14-19). En efecto, los poemas del siglo XVI dan cuenta de una presencia explícita del mundo antiguo y de la tradición épica en la cosmovisión que ordena y representa los hechos de la Guerra de Arauco. Se trata de una presencia que, en ocasiones, se hace evidente en la mención de argumentos y nombres de la tradición épica clásica, y que, en otras, se manifiesta mediante recursos que a partir de las epopeyas de la Antigüedad se hicieron propios y necesarios al discurso épico de Arauco.

Edad de Oro, XXXVI (2017), pp. 159-173, ISSN: $0212-0429$ - DOI http://dx.doi.org/10.15366/edadoro2017.36.010 
Su identificación puede ser no solo de interés al análisis literario, sino también a una perspectiva histórica que busque comprender esta influencia y los usos de ciertos recursos retóricos, a partir del contexto que inspiró la producción de estos poemas. En este sentido, nuestra hipótesis propone que la mención de nombres y pasajes de las epopeyas antiguas, aun partiendo de motivos literarios, constituye un recurso que requiere explicarse en un marco histórico. Pese a que las menciones, imitaciones o evocaciones al mundo antiguo pudieron responder a un estilo o a una cultura imitativa propia de los tiempos renacentistas, su presencia en las epopeyas sobre Arauco otorga a la materia un sentido particular, que escapa al plano estético y de lo formal: ellas responden a un ejercicio de apropiación cultural y resignificación histórica de las formas literarias de la tradición épica. Los recursos literarios sirvieron a la poetización de la materia histórica y a una representación significante de la conquista de Chile, adquiriendo así un carácter histórico que invita a comprenderlos dentro de su contexto cultural. Se trata de elementos que dieron a la materia un carácter épico para trascender sus limitaciones locales y cronológicas, y vincularse con las gestas y hombres de un pasado heroico identificado en el mundo greco-romano, universalizando su relevancia y significación, y amplificando su valor y sentido.

\section{De la mención de dioses y Seres mitológicos en la épiCa de Arauco}

Los versos de los poemas que cantan la Guerra de Arauco dan buena cuenta de la formación cultural de sus autores. Ellos se cargan de las menciones de nombres y términos que aluden a las lecturas de los poetas, y que en ocasiones han sido incluso criticados por su excesiva presencia (Menéndez y Pelayo 1948: 246). Por menciones, aludimos a la referencia explícita de un nombre, objeto o hecho proveniente de la literatura clásica antigua, mediante diversos recursos o figuras, como metonimias, perífrasis, alusiones y comparaciones.

Por supuesto, la presencia constante de estos nombres es tan numerosa, que no se hace posible registrarlos todos. Sin embargo, hay algunos que bien representan esta tendencia. Este es el caso de los nombres utilizados para designar una determinada situación, es decir, las metonimias, figura literaria que sustituyendo un nombre por otro produce la traslación o desplazamiento del significado de uno hacia otro, poetizando la narración, sin alterar el sentido de lo que se desea describir. $\mathrm{Su}$ uso se aplicó especialmente a elementos mitológicos, que se entremezclaban en algunos casos con referencias a nombres o hechos históricos de la Antigüedad. Para Picklesimer (1991: 317), tales menciones constituyen incluso un código mítico-poético construido a partir de ciertos usos literarios que no necesariamente poseen valor mitológico. Los nombres de la mitología, más bien, sirvieron a estos 
autores por constituir «la contraseña de su cultura» (Piñero 1993: 178). Ellos ofrecen un testimonio de la formación de estos poetas, y son prueba de que, en ocasiones, los hechos vividos o atestiguados por ellos pudieron haber evocado en sus mentes las situaciones y personajes que conocieron a través de sus lecturas. Se trata de una tendencia que pudo nacer de la cercanía de los poetas con las formas y contenidos de las obras clásicas, revelando la cultura auténtica o, en palabras de Chevalier (1976: 58), «la personalidad intelectual» de cada autor.

Generalmente, en los poemas sobre Arauco las metonimias consisten en la mención a una divinidad a través de la cual se alude a un objeto o situación relacionada con la función o personalidad que ella representa. Uno de los versos más reconocidos que cabe dentro de esta clasificación es el que ofrece Alonso de Ercilla en el canto I de La Araucana, cuando describía el ambiente bélico que dominaba en el sur de Chile: «Venus y Amón aquí no alcanzan parte, / solo domina el iracundo Marte» (I, 10, 7-8).

La metonimia que ofrece el nombre de Marte para aludir a la guerra es una de las más frecuentes y su constatación bien podría limitarse a dar cuenta de esta. Sin embargo, la mención no se destaca solo por su recurrencia, sino por el sentido que confiere al relato:

Ercilla tuvo que resolver un problema literario. Quería presentar aquella energía misteriosa y pavorosa que capacitaba a las gentes para su misión punitiva. Se trataba de algo extraordinario, cuya simbolización exigía un lenguaje fuera de lo común. Decir guerra es hablar una prosa chata e inexpresiva. Evocar al dios Marte significa un comienzo, pero no una realización completa. (Chapman 1978: 91)

Cada vez que uno de los poetas menciona a Marte para referirse a la guerra, otorga al acontecimiento un sentido que trasciende la normalidad, así como las limitaciones temporales y espaciales del hecho, confiriéndole fuerza y una propiedad universal. Para eso, los poetas recurrieron a figuras similares a las utilizadas por los autores antiguos, como Ercilla al evocar indirectamente en su verso IX, 24, aquellos virgilianos que hablaban en Aen. XII.331 del carro de Marte que avanzaba con el estruendo de sus armas y del galopar de sus caballos. Parecía ser Marte el verdadero gobernante de Arauco. Santisteban también personificó su nombre para responsabilizarlo de la situación que reinaba en las tierras de Chile, con el fin de ofrecer el contexto en el que insertaría su argumento: «Después que el riguroso Marte airado / puso al soberbio Arauco por el suelo» (IV ${ }^{\mathrm{a}}, \mathrm{I}, 9$, 1-2). En otros casos, algunos guerreros se asemejan a este dios, otros adquieren su furor, y la acción parece estar constantemente dominada por su ánimo. Ese es el objeto central del argumento de todos estos poemas, tal como lo sugiere, por ejemplo, Diego Arias, cuando agotado de la acción bélica decide desviar por un momento su atención: 
Quiero dejar ahora por un rato

el horrísono estruendo de atambores,

las armas, el rüido, el aparato,

y del sangriento Marte los furores. (VI, 44, 1-4)

En Arauco domado, es una indígena, Quidora, quien nombra en repetidas ocasiones al dios latino de la guerra, amplificando así el sentido de su discurso al no remitirse a los términos de su lengua originaria, como en otros casos lo había hecho Oña. «Que Marte se gobierna por su antojo» (XIV, 40, 6), dice Quidora, para referirse al estado de guerra en Arauco. Su descripción no se centra en las particularidades del territorio ni de los guerreros, sino en el ambiente que caracterizaba al momento y que lo presentaba como el espacio propio de la acción bélica ${ }^{1}$.

Neptuno y Tetis, asimismo, fueron frecuentemente mencionados en referencia al mar. En La guerra de Chile (VII, 20, 2), las naves de Quiñones aran «las espaldas de Tetis», mientras que los versos de Arauco domado y de Purén indómito aluden al mar con el nombre de su mitológico rey: «Neptuno está más llano que una vega» (Oña III, 75, 5), «Haciéndole Neptuno mil favores» (Arias VI, 68, 2), dicen los poetas para hablar de la tranquilidad de las aguas. Y así, no las caracterizaban en relación a las particularidades del océano Pacífico, sino a la condición serena de un mar indistinto, el mismo que había acogido en los relatos de la Antigüedad a navegantes como Jasón, Ulises o Eneas.

En otros casos, las figuras mitológicas y literarias de la Antigüedad se insertaron a través de recursos más complejos, como parte de construcciones perifrásticas que, aludiendo a ciertos dotes o a las historias de los personajes, caracterizaban una determinada situación. En tales casos, la perífrasis constituye una figura que confiere calidad poética y complejidad a una realidad histórica que no solo se constataba, sino que a través de estas figuras, se valoraba. Así, por ejemplo, Pedro de Oña (II, 11 y 18) y Diego Arias (II, 70) sugieren el excesivo consumo de alcohol por parte de los indígenas asociando su conducta al dominio de Baco, al que simbólicamente parecían rendir culto. Son imágenes que conciben un bando indígena con vicios en el plano moral, asociado con el paganismo que los explicaría.

Las perífrasis incorporan extensas descripciones sobre situaciones que podrían enunciarse sintéticamente, pero que embellecen el relato y lo insertan en un escenario épico que escapa de la precisión geográfica e histórica. Por ejemplo, en Arauco domado, cuando Gualeva parte en la búsqueda de Tucapel, su paso presuroso es descrito por Oña con una figura que alude al transcurso del día con el mito de Apolo y Dafne:

\footnotetext{
Menciones de Marte similares, en palabras de Quidora, también pueden leerse en Oña XV, 42, 4; XV, 55, 7; XV, 58, 8; XV, 59, 7; XVI, 27, 6; XVI, 35, 3; XVI, 52, 8.
} 
Más tiempo sobre al aire van sus plantas

que sobre las que toca por el suelo;

tú, Febo, que la ves desde tu cielo,

apriesa los caballos adelantas

y con el duro azote los quebrantas

por más apresurallos en su vuelo,

todo por alcanzalla y por habella

antes que algún laurel se forme della. (VII, 26)

La octava citada se hacía parte de una de las figuras más tradicionales para la incorporación de nombres mitológicos en el argumento de los poemas épicos, y esta es la de las horas mitológicas. Se trata de un modo poético de describir el transcurso de un día, recurso que a medida que se aleja de la precisión y concisión, configura para la acción un contexto literario que se identifica con la tradición épica clásica. Llama la atención de María Rosa Lida de Malkiel el hecho mismo de que los cultores de la epopeya histórica, como resultan ser los poetas de Arauco, «de estilo forzosamente menos florido, remontan gustosamente el tono para anunciar el amanecer o el anochecer» (1975: 150). Y es que los amaneceres mitológicos no respondían ya a una concepción mítica de la naturaleza, sino a un esfuerzo por continuar el modelo de Homero y Virgilio, buscando al mismo tiempo una nueva forma de expresarse:

Lo valioso de tan larga biografía no está, por supuesto, en la mera perduración a través de un tiempo estático, sino en la tenacidad casi patética con que este hilillo de tradición enlaza tanta vieja y nueva cultura, encerrando su increíble diversidad dentro del cerco áureo de la tutela grecorromana. (Lida de Malkiel 1975: 121)

A fin de cuentas, aun con la voluntad histórica que predominó en los poetas de Arauco, pasajes que recurrían a las figuras de Faetón, Apolo o Aurora fueron los que permitieron a estos autores recrear para su historia un mundo que se vinculaba al de los héroes del mundo antiguo, trascendiendo sus límites locales y temporales. Arauco era, como cualquier otra, una tierra en la que el amanecer inspiraba al poeta y daba inicio a acciones cuyo valor no se quedaría solo en Chile. Por ejemplo, el día en que los hombres de Villagra darían muerte a Lautaro se inicia con la descripción mitológica del amanecer en La Araucana:

Era llegada al mundo aquella hora que la escura tiniebla, no pudiendo sufrir la clara vista de la Aurora, se va en el occidente retrayendo; cuando la mustia Clicie se mejora el rostro al rojo oriente revolviendo, 
mirando tras las sombras ir la estrella y al rubio Apolo Délfico tras ella. (XIV, 7)

Oña describía también con las fórmulas heredadas de la poesía antigua el transcurso de una noche al día siguiente, para ambientar los trabajos de los españoles en un fuerte, mientras que Santisteban utilizaba este recurso centrándose en la descripción de los cielos de la ciudad de La Imperial, para distender la lectura luego del relato sobre el empalamiento a los que se había condenado a los indígenas Torquín y Tulcomara:

El tiempo que gastó la batería fue desde que asomando retoñece aquella que los campos humedece, vistiéndolos de gracia y alegría; hasta que ya la blanca flor del día de todo punto abierta resplandece, y el coronado rey de Creta y Delo quiere quemar con ellas las del suelo.

(Oña VIII, 43)
Y cuando la rosada y blanca Aurora, por el dorado Antártico Emisfero, las blancas nubes con sus rayos dora, saliendo el carro de Titán primero, de la Imperial la gente vencedora salió a ver empalado al indio fiero, que, según el semblante allí mostraba, por más vivo que muerto le juzgaba.

(Santisteban IV ${ }^{\mathrm{a}}, \mathrm{XI}, 72$ )

Son ejemplos de un recurso constante ${ }^{2}$, que se mantuvo siempre fiel al modelo clásico y que permitía la inserción de nombres de la mitología antigua en un contexto moderno y en una historia ajena, que así se hacía parte del mismo mundo y de una sola tradición.

\section{El EJEMPLO DE LOS HÉROES DE LA ANTIGÜEDAD}

Las acciones que acontecieron en tierras chilenas también podían emular directamente a las del pasado clásico, asemejándose a ellas. Así, tanto como los pasajes y personajes de la mitología clásica son mencionados en los poemas, los nombres históricos del mundo antiguo se asoman recurrentemente en sus versos. Esos personajes aparecen, por una parte, en alusiones circunstanciales que se centraban en las cualidades que estas figuras representaban y que solían constituirlas en modelos, justificándose con ello su recuerdo. «A Mario, Casio, Filón, Codro Ateniense, / Régulo, Agesilao y el Uticense», recuerda Ercilla (XXIX, 2,

\footnotetext{
$2 \quad$ Otros versos que describen las horas mitológicas son los siguientes: Ercilla II, 50; 11, 54-55; Oña VIII, 64; IX, 38; X, 9; X, 32; X, 38; XII, 14; XII, 107; XIII, 9; XVII, 15; XVIII, 32; XVIII, 90; XVIII, 106; Santisteban IV ${ }^{\text {a }, ~ I, ~ 32 ; ~ I V ~}{ }^{\text {a }}$ II, 23; IV ${ }^{\mathrm{a}}$, IV, 61; IV ${ }^{\mathrm{a}}$, VII, 38; IV ${ }^{\mathrm{a}}$, XII, 35; IV ${ }^{\mathrm{a}}$, XII, 74; $\mathrm{V}^{\mathrm{a}}$, I, 10; V $\mathrm{V}^{\mathrm{a}}$ II, 33; $\mathrm{V}^{\mathrm{a}}$, V, 60; V', VI, 15; V', XII, 71; Arias I, 18; I, 23; I, 35; I, 39; I, 50; I, 56; IV, 69; V, 24; VI, 7; VIII, 20; X, 12; XI, 33; XVI, 71; XX, 30; XXI, 16; XXIII, 41; XXIII, 62; La guerra de Chile IX, 42; XI, 15.
} 
7-8), mientras Arias (VI, 2) evoca los nombres de Valentiniano, Maximino y Cayo Mario, entre otros, como hombres cuyo valor los hacía merecedores de reconocimiento eterno.

No obstante, la presencia de tales nombres se fortaleció especialmente mediante el recurso de la comparación, que asimilaba una acción o cualidad de un personaje de la Guerra de Arauco a los de la historia del mundo clásico. La enumeración de los nombres de mujeres piadosas y amantes de sus esposos fue frecuente en estas obras. Los modelos de Dido, Andrómaca, Hécuba, Camila o Penélope eran mencionados a propósito del arrojo de algunas araucanas en la búsqueda de sus amados o por su sacrificio a favor de la causa indígena:
¡Cuántas y cuántas vemos que han subido a la difícil cumbre de la fama! Iudic, Camila, la fenisa Dido, a quien Virgilio injustamente infama; Penélope, Lucrecia, que al marido lavó con sangre la violada cama; Hippo, Tucia, Virginia, Fulvia, Cloelia, Porcia, Sulpicia, Alcestes y Cornelia.
Bien puede ser entre estas colocada la hermosa Tegualda, pues parece en la rara hazaña señalada cuanto por el piadoso amor merece. Así, sobre sus obras levantada, entre las más famosas resplandece, y el nombre será siempre celebrado, a la inmortalidad ya consagrado. (Ercilla XXI, 3-4) ${ }^{3}$

Algo similar ocurría con los personajes masculinos, cuya valentía y arrojo podía inspirar a los poetas para evocar el ejemplo de nombres históricos, como lo hizo Ercilla con Scévola, Leonidas o Marcelo, para destacar el valor de Lautaro (III, 42-43), u Oña con Escipión o Aquiles, para exaltar la figura de García Hurtado de Mendoza (I, 46-47). Los grandes nombres de la Antigüedad permitían indistintamente su comparación con españoles o indígenas, pues el fundamento axiológico de estos poemas parece haber sido uno solo.

Como es propio de la épica, ambos bandos podían ser igualmente admirables. En las obras clásicas, troyanos y aqueos, latinos y rútulos, pompeyanos y cesarianos contaron con valientes hombres y fieles mujeres. Ya fuera por seguir este

\footnotetext{
3 Comparaciones similares entre mujeres de la Antigüedad y de la Guerra de Arauco también pueden leerse en Oña VII, 20; Santisteban IV ${ }^{\mathrm{a}}$, XII, 2-7; Arias XXII, 27; La guerra de Chile VI, 48.
} 
carácter, ya por crear un enemigo digno de vencer o porque los indígenas provocaron realmente un sentimiento de admiración en estos poetas, así sucedió también con españoles y araucanos, que parecían, hasta cierto punto, compartir algunos valores. Más allá de la causa por la que luchaban, las constantes comparaciones de sus acciones con las de célebres personajes antiguos establecieron ciertos principios comunes a partir de los cuales las gestas se comprendían y se valoraban ${ }^{4}$.

En otros casos, los ejemplos del mundo antiguo sirvieron para ejemplificar los vicios en los que incurrían los protagonistas de Arauco. Nuevamente, el recurso fue utilizado tanto para conquistadores como para indígenas. La crueldad de Sila y de Nerón fue recordada por Ercilla al describir la matanza de araucanos tras el saqueo al fuerte de Tucapel (XV, 47), y la inclemencia de Lope de Aguirre también fue asociada a la del emperador romano, así como a la de Herodes (XXXVI, 38). Arias comparó el engaño de Quintegüeno a los españoles con el de Sinón a los troyanos (IV, 44), y pensaba en los estragos que el cacique Anganamón ocasionaría en las ciudades españolas como los que Aníbal causó en Sagunto (X, 27).

Las situaciones acontecidas o sentidas en Arauco, asimismo, eran comparables a ojos de los poetas con hechos memorables de la historia antigua. El saqueo e incendio de Troya, Roma y Cartago, por ejemplo, fueron frecuentemente aludidos cuando se trataba de describir el asalto o destrucción de ciudades y fuertes del sur de Chile, e incluso cuando en términos más generales los poetas requerían crear un contexto de confusión y caos $^{5}$.

No se trataba de recurrir a estos episodios por su semejanza explícita. Arauco no podría asimilarse a Roma o Troya en términos arquitectónicos, demográficos, ni menos por su relevancia política. Pero mediante el recurso de la comparación, era posible elevar poéticamente el valor del acontecimiento descrito. Así, no se comparaba tanto el detalle del hecho, cuanto su sentido y valor:

No supiera color dalle Cloantes, ni Apeles retratar lo que allí había.

¡Oh!, qué Roma, qué Troya, ¡oh! ¡Qué Cartago!

¿No daba horror, señores, tanto estrago? (La guerra de Chile, VIII, 10)

$4 \quad$ Kallendorf (2003) analiza, en este sentido, la influencia de la Eneida sobre la construcción de los personajes de La Araucana, para dilucidar si sobre la valoración de cada bando se imponían estereotipos ideológicos. Esto, considerando que comúnmente se piensa en La Araucana como un poema imperialista o bien como un poema lascasiano, y que en cualquiera de los dos casos ofrecería una visión maniquea del conflicto. En opinión de Kallendorf, la construcción y valoración de los personajes de cada bando no establecería una distinción tan sencilla entre ellos. Precisamente en esta ausencia de diferencias claras, la obra de Ercilla se asimilaría a la Eneida, ya que en ambos poemas la actitud del autor frente a la empresa imperial no podría simplificarse.

5 Comparaciones en estos términos pueden leerse en Ercilla VII, 48; XXIV, 42; Oña III, 103; V, 56; Arias VIII, 11; IX, 78; XV, 65; XIX, 34; La guerra de Chile, VIII, 10; VIII, 50; X, 63. 
A través de la alusión a la destrucción de Ilión o de Roma, las consecuencias de la Guerra de Arauco se proyectaban más allá de las repercusiones directas del conflicto, pues este dejaba poéticamente de ser un asunto periférico, para pasar a ser relevante y universal.

Los ejemplos son numerosos. Cada obra aportó con nombres, situaciones y acontecimientos que evocaban al mundo clásico, y que podrían constituir una extensa lista de la cual se desprende el conocimiento de los poetas sobre la historia antigua, así como su formación humanista y las lecturas que la forjaron.

\section{LOS RECURSOS LITERARIOS PARA LA REPRESENTACIÓN SIMBÓLICA DE LA GUERRA DE ArAuCo}

Aun cuando los recursos literarios utilizados eran formalmente semejantes, el catálogo de menciones y alusiones específicas en estos poemas difirió para cada uno: aunque los cinco autores utilizaron metonimias, perífrasis, alusiones circunstanciales y comparaciones basadas en nombres mitológicos e históricos del mundo antiguo, cada uno recurrió a ellos en diversos grados. En este sentido, el carácter de la obra y la intención de cada poeta pudieron determinar los tipos de nombres y pasajes que primaron en cada poema. De este modo, a mayor voluntad histórica del autor, mayor fue la recurrencia a nombres históricos de la Antigüedad. Es el caso de Alonso de Ercilla y de Diego Arias, cuyos poemas contienen proporcionalmente menos pasajes de ficción. En el caso de La Araucana, incluso la vida de la reina Dido (XXXII y XXXIII) fue abordada por Ercilla a partir de la versión histórica de Timeo y Justino, desmintiendo el mito desarrollado por Virgilio en la Eneida.

Diego Arias, por su parte, aun mencionando recurrentemente a divinidades mitológicas como Marte y Belona, acudió de manera constante a comparaciones y evocaciones de la historia romana. Recuerda en más de una ocasión, por ejemplo, pasajes de las Guerras Púnicas (III, 16; IX, 78; XII, 22), gobernantes y emperadores romanos (VI, 1-5; X, 3; XIX, 34; XX, 68-69), o algunas prácticas latinas, como los desfiles militares que celebraban las victorias y hacían gala de sus conquistas sobre los vencidos (III, 7).

Los nombres mitológicos, en cambio, parecen haber estado presentes en ambas obras, más en razón del estilo épico que por una intención de completar el relato con pasajes fantásticos. Ellas conferían, sí, ese sentido universal y epopéyico a la historia, pero no alcanzaban a poetizar excesivamente la acción ${ }^{6}$. En $L a$

6 Incluso así ocurrió en La Araucana, con los pasajes sobre la batalla de San Quintín (XVII-XVIII) y el combate de Lepanto (XXVI-XXVII). En el primer caso, Ercilla insertó el relato mediante el recurso de lo onírico, de modo que la aparición de Belona, si bien refería al mito, no resultaba del todo fantástica. En el caso de Lepanto, aunque la visión que el mago Fitón ofrecía a Ercilla podía 
Araucana y Purén indómito, la historia se orna de poesía, pero no se deforma por ella. El carácter épico parecía inherente a las acciones que relataban, y no requería de su exaltación mediante la ornamentación retórica.

Distinto fue el caso de los demás poemas. Más mitológicas son las menciones, alusiones y comparaciones que se leen en Arauco domado, en Cuarta y quinta parte de La Araucana, y en La guerra de Chile, donde la fantasía parece competir, e incluso sobreponerse en algunas oportunidades, a la historia narrada.

Ovidio y Virgilio constituyeron referentes importantes para Oña y Santisteban (Castro y Zapata 2009). Y en La guerra de Chile es posible leer los nombres de figuras mitológicas asociadas especialmente con creencias astrológicas, formuladas en obras antiguas como los Phaenomena de Arato o las Fábulas y la Astronómica poética de Higinio. Particularmente, en las largas disgregaciones insertas en este anónimo poema (X y XI), así como en las desarrolladas por Santisteban ( $\mathrm{V}^{\mathrm{a}}$, VIII-IX), asoman con mayor fuerza nombres como los de Apolo, Dafne, Filomena, Ariadna, Ortosia y Polifemo, entre otros.

Oña fue uno de los que más se extendió en argumentos que escapaban a los hechos de la Guerra de Arauco, sobre todo desde el canto XIV. Aun tratando sobre acontecimientos del sur de Chile, este poeta buscó siempre ornar los hechos con pasajes que superaban las limitaciones del hito histórico y que incluso ficcionalizaban el relato, como hizo con el concilio de las fuerzas infernales (IV) o con el idilio de Caupolicán y Fresia (V).

La diferencia en los tipos y usos de las menciones utilizadas por cada poeta hablan de su diversa intención, pero también de su particular formación, de sus lecturas y del momento histórico que cada uno vivió. Claramente, el caso de Santisteban puede ofrecer la explicación más simple. El poeta nunca viajó a Chile. Su inspiración fue indirecta y literaria: conoció la Guerra de Arauco por La Arauca$n a$ y la imaginó en base a ella y a la tradición épica que debió haberlo fascinado. Desde el prólogo, el poeta vinculó la gloria de Chile con la del pasado romano, y lo hizo en los términos con los que Ercilla había definido, en su canto I, el valor y la indomabilidad del pueblo araucano:

Grande fue la gloria que los Romanos antiguos por las armas alcanzaron, pues vive en nuestros tiempos su memoria, como vemos en los famosos Césares, cuya fama ha llegado hasta el empíreo cielo, que no puede callarla silencio, ni encubrirla olvido. [...] Aunque si bien se mira, no fueron tan grandes sus hechos como los que hicieron los indómitos Araucanos, por resistir el valor y pujanza tanto tiempo de nuestros Españoles: que si el famoso Scévola por errar un golpe se abrasó la

resultar fantasiosa, dejaba la responsabilidad del elemento mágico al personaje araucano, que así no representaba tanto un elemento de ficción, sino que se escudaba en la imagen de lo otro y de lo exótico, fortalecido con elementos de la tradición literaria - como los que evocaban la caverna de Ericto en Farsalia - , que reforzaban el contenido del pasaje. 
mano, estos famosos Indios, por no recibir el de su contraria fortuna, ofrecieron su hacienda y vidas, poniendo en ellos los Españoles el yugo que nunca habían en sus cervices hasta allí consentido. (Santisteban: Prólogo)

Su intención no era hacer crónica rimada ni dejar testimonio cierto de los hechos. Tal como Santisteban declaró luego en el mismo prólogo, el poema surgía de su voluntad poética por dar continuación al de Ercilla, y esa filiación no parecía asegurarse tanto a través del argumento histórico cuanto de la tradición que le confería sentido y valor. Las menciones constantes a los nombres y personajes del mundo clásico en Cuarta y quinta parte de La Araucana adquirían, en ese sentido, un rol que trascendía a la obra en sí misma.

En el caso de Oña, su formación universitaria en Lima debió influir en su esfuerzo por insertar los elementos literarios con los que se había educado. El resultado es una obra más lírica que las epopeyas de Ercilla y de Arias, hombres que sí participaron activamente de la guerra que describieron. Sin la experiencia constante de la guerra, el autor de Arauco domado, en opinión de Menéndez y Pelayo (1948: 242), se nota más cómodo con lo ameno y florido antes que con lo heroico, restando así vigor a su narración y confiriéndole, en cambio, una belleza que habla de una vida que corrió lejos del campo de batalla (Avalle Arce 1985: 161). Además, no puede dejarse de lado la intención de Oña de hacer justicia a la figura de García Hurtado de Mendoza, por la cual realizó una obra que subjetivaba y relativizaba la historia a su protagonista. La figura del Marqués de Cañete inspiró la pluma del poeta, tal como él mismo solicitó en su exordio, evocando la travesía de César en la barca de Amiclas antes de la batalla de Farsalia:

El vulgo fácil es el mar hinchado; es la barquilla frágil, mi talento, yo soy el pobre Amiclas tremulento, del recio temporal amedrentado; Mas sedme vos el César, don Hurtado, pues mucho más tenéis de nacimiento, y no me detendrá temor de Scila, ni fiera boca rábida y zoíla ${ }^{7}$. (Exordio, 11)

El autor se arrogó mayores libertades para la poetización de su materia y se sirvió de los recursos que las obras clásicas le ofrecían para exaltar las gestas del gobernador, que debía estar a la altura de los grandes héroes antiguos. Los nombres de personajes mitológicos, divinidades y héroes del mundo clásico elevaban la calidad de las gestas de García Hurtado de Mendoza y de sus hombres, que no

$7 \quad$ Nombre adjetivado de Zoylo, crítico negativo de Homero y prototipo de la envidia.

Edad de Oro, XXXVI (2017), pp. 159-173, ISSN: 0212-0429 
se enfrentaban solo a un conflicto en el Nuevo Mundo, sino que se hacían parte de la lista de aquellos célebres nombres que la tradición épica guardaba por sobre las restricciones históricas. Las recurrentes menciones recuerdan que los héroes de Arauco participaron de un mismo universo épico con los héroes de la Antigüedad, y que sus gestas, por tanto, poseían un valor que trascendía la localidad del conflicto.

Similar, en este sentido, fue el caso de La guerra de Chile, sobre todo en un excurso sobre la travesía de unos marinos holandeses (X-XI), donde la tradición clásica se hacía sentir mediante numerosos tópicos y menciones. Precisamente, se trata de un pasaje que traspasaba las fronteras de Chile, y que insertaba el conflicto de Arauco en un escenario espacial, cronológica e históricamente más amplio, aunque, quizás, con una motivación distinta. A diferencia de Santisteban y de Oña, el autor de La Guerra de Chile dice haber participado en las batallas de Arauco (V, 67-68). Por su naturaleza testimonial, el poema podría haber otorgado primacía a los hechos históricos y a la objetividad descriptiva del relato. Sin embargo, aunque sus primeros cantos se centran en la narración de los hechos de guerra, poco a poco escapan al conflicto para agregar figuras de la tradición clásica que representarían, con menor precisión y mayor lirismo, acontecimientos más propios del universo mitológico y literario que del mundo histórico de la Guerra de Arauco.

Los motivos de este cambio hacia una perspectiva más literaria y subjetiva podrían deberse a la disposición con la que el poeta concibió la guerra. Las primeras octavas expresan bien que su percepción de la Guerra de Arauco difería de la de sus predecesores, primando la crítica y el lamento por sus excesos de violencia (Triviños y Rodríguez 1996: 42):

La guerra envejecida y larga canto, tan grave, tan prolija y tan pesada, que a un reino poderoso y rico tanto le tiene la cerviz ya quebrantada.

(La guerra de Chile I, 1, 1-4)

Se trata de un comienzo que reconocía versar sobre el mismo asunto que los poemas precedentes, pero que se hacía, a su vez, diferente. Los versos hablaban de una guerra ya agotada, que no parecía inspirar esa perspectiva épica de los hechos que, en cambio, parecían haber constituido la motivación inicial de Alonso de Ercilla. De esta forma, las menciones a los personajes y hechos del mundo antiguo pudieron servir al autor para distanciarse de una materia ante la cual adoptó una perspectiva crítica. Al carecer de un argumento central y de un protagonista heroico, el poema llenó sus cantos con los argumentos que la tradición clásica le 
ofrecía (Triviños y Rodríguez 1996: 50). Por otra parte, los elementos de la tradición clásica pudieron asumir un rol específico: el de otorgar a los hechos narrados ese tono épico que no parecía surgir de ellos mismos. A fines del siglo XVI, la guerra se había vuelto constante y perdía su aspecto lejano e ideal. Arauco no parecía ya esa tierra de héroes de La Araucana, de cuyo imaginario dieron también cuenta Oña y Santisteban.

La visión de los acontecimientos que poseía el autor de La guerra de Chile se confirma, en cambio, con la que caracterizó asimismo al poema de Diego Arias. Si bien Purén indómito es un poema de carácter más histórico, la perspectiva de su autor frente a la guerra fue también crítica. El poema de Arias tampoco posee un héroe claramente definido, aun cuando Francisco de Quiñones se encamine a serlo. Las menciones de los personajes clásicos se asoman en La guerra de Chile y Purén indómito, ante todo, como referentes morales o recursos retóricos, pero no como nombres cuya evocación surgiera del entusiasmo épico que antes ofrecía la Guerra de Arauco. Antes que comparaciones, el recurso más usual fue, en este sentido, la metonimia y la alusión circunstancial, figuras que no asociaban un objeto a otro en virtud de su cualidad, sino que insertaban desde fuera, desde la tradición épica, el carácter epopéyico que no emanaba desde la historia.

La inspiración fue cambiando progresivamente en la tradición poética que el modelo de La Araucana había fundado. Así, aun siendo constantes las menciones de los nombres de la Antigüedad en cada poema sobre la Guerra de Arauco, sus usos fueron diversos. Si bien podemos hablar de los ecos de la tradición clásica y de la huella de Ercilla en los poemas de Oña, Santisteban, Arias y La guerra de Chile, estos deben pensarse como una resonancia o como un camino que se proyectó y que necesariamente cambió. Los clásicos mantuvieron su presencia en estos poemas, pero en modos distintos, por un motivo histórico, que hacía de los autores no solo testigos imparciales o cronistas objetivos de la conquista de Chile. Cada uno, aun recurriendo a modelos literarios compartidos, representó la misma historia desde ópticas diversas, conforme al momento histórico y a las vivencias particulares que les correspondieron.

El uso continuo de los recursos ofrecidos por la tradición clásica confirma la calidad de los poemas épicos y de los personajes de la Antigüedad en cuanto clásicos. Esos que no se insertaron en estas obras por una simple razón de estilos, y que no mantuvieron siempre una misma forma. Son esos clásicos que, por el contrario, fueron objeto de adaptación, sirviendo a cada poeta para comprender y expresar sus particulares ideas y sentimientos respecto del mundo, siempre distinto, que los rodeó, y para darlos a conocer a quienes se habían educado en el mismo lenguaje universal de la tradición épica. 


\section{BIBLIOGRAFÍA}

Anónimo (1996). La guerra de Chile. Edición crítica de Mario Rodríguez Fernández. Santiago de Chile: Universidad de Chile.

Arias de SaAVedra, Diego (1984). Purén indómito. Edición de Mario Ferreccio Podestá. Santiago de Chile: Biblioteca Nacional.

Avalle-ArCE, Juan B. (1985). «Pedro de Oña ante la epopeya». Filología, XX, 2, pp. 152170.

Castro, María Dolores, y ZaPATA, Almudena (2009). «Tópicos épicos de cuño virgiliano en el Arauco domado de Pedro de Oña». En Trinidad Arcos, José Fernández López y Francisca Moya del Baño (eds.), 'Pectora mulcet'. Estudios de retórica y oratoria latinas. Logroño: Instituto de Estudios Riojanos, pp. 277-289.

Champman, Arnold (1978). «Ercilla y el furor de Marte». Cuadernos Americanos, año XXXVII, vol. CCXXI, 6, pp. 87-97.

Chevalier, Maxime (1976). Lectura y lectores en la España del siglo XVI. Madrid: Turner.

Ercilla y Zúñiga, Alonso de (2002). La Araucana. Edición de Isaías Lerner. Madrid: Cátedra, $3^{\mathrm{a}}$ edición.

HighET, Gilbert (1947). «Classical echoes in La Araucana». Modern Language Notes, LXII, pp. 329-331.

KALLENDORF, Craig (2003). «Representing the other: Ercilla's La Araucana, Virgil's Aeneid, and the New World encounter». Comparative Literature Studies, vol. 40.4, pp. 394414.

Lida de Malkiel, María Rosa (1975). La tradición clásica en España. Barcelona: Ariel.

McManamon, James (1955). Echoes of Virgil and Lucan in the Araucana. Illinois: UMI Disertation Services.

MenÉndez y Pelayo, Marcelino (1948). Historia de la poesía hispanoamericana. Madrid: Consejo Superior de Investigaciones Científicas.

OÑA, Pedro de (1917). Arauco domado. Edición Crítica de la Academia Chilena por José Toribio Medina. Santiago de Chile: Imprenta Universitaria.

PICKLESIMER, María Luisa (1991). «El tratamiento del mito en la literatura del humanismo». En José Antonio Sánchez y Manuel López (eds.), Humanismo renacentista y mundo clásico. Madrid: Ediciones Clásicas, pp. 301-220.

PIÑERo RamíreZ, Pedro (1993). «La épica hispanoamericana colonial». En Luis Íñigo Madrigal (coord.), Historia de la literatura hispanoamericana. Madrid: Cátedra, I, pp. 161-188.

SAntisteban Osorio, Diego de, Cuarta y quinta parte de La Araucana (1597). Salamanca: Casa de Juan y Andrés Renaut.

Triviños, Gilberto, y RodrígueZ, Mario (1996). «La clausura de la epopeya en La guerra de Chile». Estudios Filológicos, 31, pp. 39-56.

Recibido: 12/10/2017

Aceptado: 25/11/2017 


\section{\%}

\section{RECURSOS LITERARIOS DE LA ÉPICA CLÁSICA PARA LA REPRESENTACIÓN DE LA GUERra de ARAuCO EN EL SIGLO XVI}

RESUMEN: El artículo analiza algunos recursos literarios utilizados en los poemas épicos sobre la Guerra de Arauco en el siglo XvI, que hicieron uso de nombres y pasajes del mundo antiguo griego y romano. El análisis propone un enfoque de interpretación histórica, que comprende el uso de tales recursos como un ejercicio de recepción de la tradición clásica por parte de los poetas, para amplificar los alcances de su argumento y representar la guerra en una condición trascendente y universal.

PALABRAS ClAVE: tradición clásica, guerra de Arauco, poesía épica, recursos literarios.

\section{LITERARY RESOURCES OF THE CLASSICAL EPIC POETRY}

FOR THE REPRESENTATION OF THE ARAUCO WAR IN THE SIXTEENTH CENTURY

ABSTRACT: The article analizes some literary resources of the epic poems on the Arauco War in the 16th century, which used names and passages from the ancient Greek and Roman world. The analysis proposes an approach of historical interpretation, which understands the use of such resources as an exercise of reception of the classical tradition by the poets, to amplify the scope of their argument and to represent the war with a transcendent and universal condition.

Keywords: Classical Tradition, War of Arauco, Epic Poetry, Literary resources. 


\section{EDAD DE ORO}

Revista de Filología Hispánica XXXVI

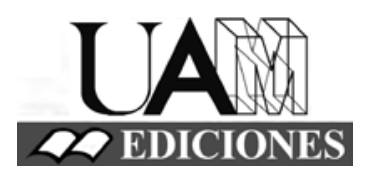




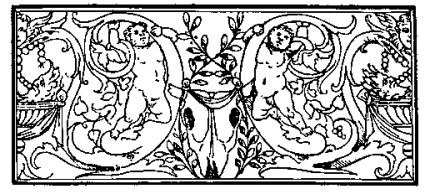

\section{Edad de Oro. Revista de Filología Hispánica}

ISSN: 0212-0429

Dirección:

Teodosio Fernández

Secretaría y edición:

José Ramón Trujillo

Consejo de redacción:

Manuel Piqueras

Blanca Santos

Admisión de originales:

María Jesús Zamora

Edad de Oro

Departamento de Filología Española

Universidad Autónoma de Madrid

28049 Madrid (España)

Tfno.: +0034914974090

correo: mariajesus.zamora@uam.es

Distribución, suscripción y venta:

Servicio de Publicaciones de la UAM

Universidad Autónoma de Madrid

28049 Madrid (España)

Intercambio de publicaciones:

Biblioteca de la Facultad de Filosofía y

Letras (UAM)

Universidad Autónoma de Madrid

28049 Madrid (España)
Comité científico internacional:

Carlos Alvar (Univ. de Ginebra)

Ignacio Arellano (Univ. de Navarra)

Javier Blasco (Univ. de Valladolid)

Alberto Blecua (UAB)

Jean Canavaggio (Univ. de París X)

Laura Dolfi (Univ. de Turín)

Aurora Egido (Univ. de Zaragoza)

Víctor García de la Concha (RAE)

Luciano García Lorenzo (CSIC)

Joaquín González Cuenca (Univ. de

Castilla-La Mancha)

Agustín de La Granja (Univ. de Granada)

Begoña López Bueno (Univ. de Sevilla)

Michel Moner (Univ. de Toulouse III)

Joan Oleza (Univ. de Valencia)

Alfonso Rey (Univ. de Santiago)

Lina Rodríguez Cacho (Univ. de Salamanca)

Leonardo Romero Tobar (Univ. de Zaragoza)

Aldo Ruffinatto (Univ. de Turín)

Lía Schwartz (City University of New York)

Han colaborado en este volumen:

Departamento de Filología Española (UAM)

Facultad de Filosofía y Letras (UAM)

Edad de Oro se recoge, entre otras, en las siguientes bases de datos: SCOPUS, MLA Database, HLAS, Latindex, PIO-Periodical Content Index, ISOC, Dialnet, MIAR, ERIH Plus, DICE, Sumaris CBUC, Ulrich's. Se encuentra evaluada en CIRC: A; MIAR difusión ICDS live 2016: 10.0; INRECH; SCImago Journal \& Country Rank: H Index 3, SJR SCImago Journal \& Country Rank 0,1, Q4; RESH índice de impacto: 0.041; ERIH: A INT1; Carhus Plus+2014: C. 